\title{
Relationships between Organic Material and Thermal Maturity Derived from Coal and C-Shale Samples
}

\author{
Louis L. Tsai ${ }^{1,}{ }^{*}$, Huey-Jane Hsieh ${ }^{1}$, Hsien-Tsung Lee ${ }^{2,3}$, and Li-Chung Sun ${ }^{3,4}$ \\ ${ }^{1}$ Institute of Applied Geology, National Central University, Chung-Li, Taiwan, ROC \\ ${ }^{2}$ Institute of Geophysics, National Central University, Chung-Li, Taiwan, ROC \\ ${ }^{3}$ Department of Electric Engineering, Nankai Institute of Technology, Nantou, Taiwan, ROC \\ ${ }^{4}$ Graduate Institute of Electrical Engineering \& Computer Science, Nankai Institute of Technology, Nantou, Taiwan, ROC
}

Received 16 February 2007, accepted 23 October 2007

\begin{abstract}
The purpose of this study is to characterize the relationship between organic material and thermal maturity during the process of evaluation of hydrocarbon potential. Samples studied include Miocene high volatile bituminous coal and coaly shale collected from outcrops and exploration wells in Hsinchu-Miaoli area, NW Taiwan, density centrifuge separated macerals, bituminous coal and anthracite from China, in addition to Woodford and Green River oil shale from the United States. Maceral composition analysis, elemental analysis, vitrinite reflectance measurement and Rock-Eval pyrolysis were performed for evaluation. The results of study show that: 1) coal samples from the Shiti Formation (middle Miocene) exhibit more vitrinite and less mineral matter contents than samples from the Nanchuang Formation (upper Miocene); $\mathrm{H} \%$ is increased in exinite-enriched maceral mixtures with density $<1.25 \mathrm{~g} \mathrm{~cm}^{-3}$, after density centrifuge separation. 2) A positive linear correlation between Tmax and Ro illustrates both Rock-Eval pyrolysis and vitrinite reflectance can be used as indicators of thermal maturity. 3) From the plot of $\mathrm{H} / \mathrm{C}$ ratio vs. vitrinite reflectance, even though the depositional environments were different in Taiwan and China, their organic micelles exhibit a similar trend in the process of thermal maturation. As a whole, the curve has a turning point at $\mathrm{Ro}=0.5 \%$ and $\mathrm{H} / \mathrm{C}=0.1$ (atomic ratio 1.2) in this study. 4) A rather good correlation between $\mathrm{S} 2$ and TOC of samples studied indicates the contribution of S2 from TOC. 5) The highest HI occurred in certain maturities (Tmax and Ro) of samples studied, and not in the stages of less maturity or over-maturity. 6) Two different linear trends were observed in the cross plot of S1 vs. S2. Field outcropped shale or C-shale exhibits a steeper slope compared to that of coal samples which can be attributed to the compositional difference in their organic material. 7) A rather strong positive correlation for $\mathrm{H} \%$ vs. S2 illustrates the contribution of H-containing macerals, especially exinite. As a result of this study, we expect to promote evaluation techniques for $\mathrm{HC}$ exploration; for instance, the development or improvement of evaluation methods for source rocks, reservoirs, structural evolution, and thermal maturity. Evaluations are expected to give more detail regarding local conditions, and be better quantified and more accurate.
\end{abstract}

Key words: Organic material, Thermal maturity, Coal

Citation: Tsai, L. L., H. J. Hsieh, H. T. Lee, and L. C. Sun, 2008: Relationships between organic material and thermal maturity derived from coal and C-shale samples. Terr. Atmos. Ocean. Sci., 19, 489-495, doi: 10.3319/TAO.2008.19.5.489(TT)

\section{INTRODUCTION}

Evaluation of hydrocarbon potential is one of the most important aspects of oil exploration (Dow 1974). Its precision relates to the prediction of locations and reserves of prospect areas and the outcome of exploration projects (Magoon and Dow 1994). A hydrocarbon reserve can be ge-

* Corresponding author

E-mail:ltsai@geo.ncu.edu.tw nerated by a proper combination of good source rock, depositional and tectonic structures, and thermal maturation (Otis and Schneidermann 1997). Therefore, "Material" and "Maturity" (M \& M) of the hydrocarbon are the two important topics in evaluation.

The purpose of this study is to characterize the relationships between organic material and thermal maturity. 42 samples studied include Miocene high volatile bituminous 
coal and coaly shale plus kerogen and organic matters recovered from exploration wells in NW Taiwan, coal samples (aged from Devonian to Tertiary) from China, Green River (Eocene) and Woodford shale (Permian) from the USA, in addition to maceral mixtures prepared by density centrifuge separation of $\mathrm{ZnCl}_{2}$ solution as proposed by Dormans et al. (1957). Maceral composition analysis, elemental analysis, vitrinite reflectance measurement and Rock-Eval pyrolysis were performed to evaluate the characteristics of organic materials and maturities.

\section{LITERATURE REVIEW OF LOCAL GEOLOGIC SETTINGS}

Taiwan is located in an active arc-continent collision zone between the Eurasian Plate and Philippine Sea Plate. The so-called Penglai Orogeny starting from Plio-Pleistocene led to the lifting of the Central Mountain Range and the exposure of small-sized hydrocarbon fields, especially on the northwestern part of the Western Foothills Belt of Taiwan. Three coal-containing cyclothems occurred in Miocene formations, namely the Nanchuang Formation, Shiti Formation and Mushan Formation, respectively from top to bottom. Various methods have been developed for oil and gas exploration in the past, such as thermal studies (Lin 2000), basin analyses (Chi et al. 1987), and tectonic structure studies (Hwang and Wang 1993). Chiu (1972, 1975) finished a detailed Miocene stratigraphic study in westerncentral Taiwan. Afterwards, a Cenozoic basin study of offshore Taiwan was done by Sun $(1982,1985)$. In addition, Liou and Hsu (1988) followed by Hsiao et al. (1991) completed thorough studies on the evaluation of hydrocarbon potential. Furthermore, Huang $(1984,1986)$ combined paleontology, stratigraphy and geodynamics to improve the un- derstanding of local geologic settings.

\section{METHODS}

The material study starts from the collection of coal samples with maturity close to the early oil window, various maceral groups were then prepared by using density centrifuge separation. Rock-Eval pyrolysis and elemental (N, C, $\mathrm{S}$, and $\mathrm{H}$ ) analysis were then performed to evaluate the relationship between hydrocarbon potential and maceral composition. Secondly, for the collections of kerogen or organic matter having the same maturity but different hydrocarbon potentials, the maceral compositions were compared with the results of their pyrolysis and elemental analysis, so as to study the mechanism of hydrocarbon generation.

Furthermore, a maturity study was performed on the collections of coal or kerogen samples that showed maturity within the oil window and the relationship among their vitrinite reflectance and Rock-Eval pyrolysis were studied.

Maceral analysis and vitrinite reflectance measurements were performed on polished pellets using a Leitz MPV Compact Microscope, whereas elemental analysis and Rock-Eval pyrolysis were performed in the Precise Instrument Center of National Science Council and EDRI of Taiwan Chinese Petroleum Corp., respectively.

\section{RESULTS}

The analytic results of maceral composition, elemental $(\mathrm{N}, \mathrm{C}, \mathrm{S}$, and $\mathrm{H})$ composition, vitrinite reflectance and Rock-Eval pyrolysis from the 42 samples studied are listed in Table 1. Coal samples from the Shiti Formation (middle Miocene) exhibit more vitrinite and less mineral matter contents than samples from the Nanchuang Formation (upper

Table 1. Analytic results of the 42 samples studied. Sample \#1 - 24: coals from Taiwan, (SF): Shiti Formation, (NF): Nanchuang Formation; \#25 28: oil shales from the USA; \#29 - 40: coals from China, (D): Devonian, (C): Carboniferous, (P): Permian, (J): Jurassic, (Cr): Cretaceous, (T): Tertiary; \#41 - 42: coals from exploration well of Taiwan with depth (feet) in parenthesis, (MF): Mushan Formation. V, E, I, MM\% stand for vitrinte, exinite, inertinte and mineral matter $\%$, respectively in maceral analysis; $\mathrm{N} \%, \mathrm{C} \%, \mathrm{~S} \%, \mathrm{H} \%$ and $\mathrm{H} / \mathrm{C}$ are from elemental analysis; Ro(\%): vitrinite reflectance; Tmax, S1, S2, HI, TC, and IOC all from Rock-Eval Pyrolysis. Some of the elemental analysis and IOC were not detected due to cost.

(a) Description, petrographic, and chemical analyses results for samples \#1 - 24.

\begin{tabular}{|c|c|c|c|c|c|c|c|c|c|c|c|c|}
\hline NO \# & \multicolumn{2}{|c|}{ Sample Name } & V\% & E\% & $\mathbf{I} \%$ & ММ\% & N\% & $\mathrm{C} \%$ & S\% & H\% & $\mathrm{H} / \mathrm{C}$ & Ro (\%) \\
\hline 1 & \multirow{3}{*}{$\begin{array}{l}\text { Li Feng } \\
\text { (SF) }\end{array}$} & 1 & 60.6 & 5 & 29.6 & 4.8 & 1.05 & 73.18 & 0.72 & 4.77 & 0.065 & 0.739 \\
\hline 2 & & 2 & 95 & 1 & 0.8 & 3.2 & 1.20 & 61.37 & 0.15 & 5.32 & 0.087 & 0.529 \\
\hline 3 & & 3 & 68.8 & 2.4 & 0.2 & 28.6 & 1.39 & 66.18 & 2.36 & 4.93 & 0.074 & 0.582 \\
\hline 4 & \multirow{6}{*}{$\begin{array}{l}\text { Ming Deh } \\
(\mathrm{NF})\end{array}$} & 1 & 46.6 & 0.6 & 0 & 52.8 & -- & -- & -- & -- & -- & 0.411 \\
\hline 5 & & 2 & 63.2 & 1.4 & 0 & 29.2 & -- & -- & -- & -- & -- & 0.416 \\
\hline 6 & & 3 & 55.6 & 0.8 & 0.2 & 43.4 & -- & -- & -- & -- & -- & 0.445 \\
\hline 7 & & 4 & 53.4 & 1.4 & 0.6 & 44.6 & -- & -- & -- & -- & -- & 0.467 \\
\hline 8 & & 5 & 56.4 & 2. & 0.2 & 41.4 & -- & -- & -- & -- & -- & 0.47 \\
\hline 9 & & 6 & 71 & 0.8 & 0 & 28.2 & -- & -- & -- & -- & -- & 0.462 \\
\hline
\end{tabular}


Table 1. (Continued)

\begin{tabular}{|c|c|c|c|c|c|c|c|c|c|c|c|c|}
\hline NO\# & \multicolumn{2}{|c|}{ Sample Name } & V\% & E\% & $1 \%$ & ММ\% & N\% & $\mathrm{C} \%$ & S\% & H\% & $\mathrm{H} / \mathrm{C}$ & Ro (\%) \\
\hline 10 & \multirow{4}{*}{$\begin{array}{l}\mathrm{MT} \\
(\mathrm{NF})\end{array}$} & 1 & 58.2 & 0.8 & 0 & 41 & -- & -- & -- & -- & -- & 0.497 \\
\hline 11 & & 2 & 43.2 & 1.2 & 0 & 55.6 & -- & - & -- & -- & -- & 0.425 \\
\hline 12 & & 3 & 36 & 4.2 & 1.8 & 58 & -- & -- & -- & -- & -- & 0.339 \\
\hline 13 & & 4 & 51.2 & 1.8 & 0 & 47 & $-{ }^{--}$ & --- & --- & -- & --- & 0.418 \\
\hline 14 & \multirow{4}{*}{$\begin{array}{l}\text { Ming Deh } \\
\text { (NF) }\end{array}$} & $\mathrm{Wt}$ & 53.2 & 1.2 & 0 & 45.6 & 0.73 & 42.14 & 2.69 & 4.12 & 0.098 & 0.386 \\
\hline 15 & & $\mathrm{~Wb}$ & 30.2 & 1.4 & 0 & 68.4 & 0.42 & 18.93 & 0.82 & 2.13 & 0.113 & 0.52 \\
\hline 16 & & Et & 66.2 & 0.6 & 0.2 & 33 & 0.82 & 45.39 & 2.4 & 4.08 & 0.090 & 0.518 \\
\hline 17 & & $\mathrm{~Eb}$ & 3.8 & 0 & 0 & 96.2 & 0.16 & 2.2 & 0.34 & 0.34 & 0.155 & 0.357 \\
\hline 18 & \multirow{5}{*}{$\begin{array}{l}\text { Yu Feng } \\
\text { (SF) }\end{array}$} & $\mathrm{O}$ & 93.2 & 1.2 & 0.6 & 5 & 1.71 & 76.97 & 0.98 & 5.79 & 0.075 & 0.738 \\
\hline 19 & & $\mathrm{~d}<1.25$ & 84. & 11.4 & 0 & 4.6 & 1.62 & 78.39 & 0.87 & 5.91 & 0.075 & 0.682 \\
\hline 20 & & $\mathrm{~d}>1.25$ & 92.8 & 4.4 & 0.2 & 2.6 & -- & -- & -- & -- & -- & 0.707 \\
\hline 21 & & $1.25<\mathrm{d}<1.35$ & 93.2 & 3 & 1.6 & 2.2 & 1.69 & 77.61 & 0.83 & 5.20 & 0.067 & 0.747 \\
\hline 22 & & $\mathrm{~d}>1.35$ & 81.6 & 3.6 & 4.8 & 10 & 1.37 & 59.17 & 3.47 & 4.22 & 0.071 & 0.726 \\
\hline 23 & \multicolumn{2}{|c|}{ Heng Shan (NF) } & 95.4 & 0.4 & 0 & 4.2 & 0.3 & 57.24 & 0.39 & 5.12 & 0.089 & 0.23 \\
\hline 24 & \multicolumn{2}{|c|}{ Wu Chi Shan (NF) } & 33.2 & 1.2 & 0 & 65.6 & 1.73 & 73.26 & 0.83 & 6.75 & 0.092 & 0.356 \\
\hline
\end{tabular}

(b) Rock-Eval Pyrolysis results for samples \#1 - 24.

\begin{tabular}{ccccccccc}
\hline NO \# & Tmax $\left({ }^{\circ} \mathbf{C}\right)$ & S1 (mgHC/g) & S2 (mgHC/g) & $\begin{array}{c}\text { HI (S2/TOC) } \\
\mathbf{m g H C} / \mathbf{g T O C}\end{array}$ & TC (\%) & TOC (\%) & IOC (\%) & S (\%) \\
\hline 1 & 434 & 1.28 & 111.28 & 148.063 & 75.157 & 75.157 & -- & 0.830 \\
2 & 431 & 0.68 & 83.51 & 133.371 & 62.615 & 62.615 & -- & 0.298 \\
3 & 429 & 1.35 & 138.93 & 205.254 & 67.687 & 67.687 & -- & 1.342 \\
4 & 425 & 2.89 & 86.05 & 207.484 & 41.473 & 41.473 & -- & 1.470 \\
5 & 424 & 3.64 & 94.27 & 220.938 & 42.668 & 42.668 & -- & 1.213 \\
6 & 423 & 3.33 & 97.48 & 242.198 & 40.248 & 40.248 & -- & 2.003 \\
7 & 424 & 2.2 & 69.09 & 167.094 & 41.348 & 41.348 & -- & 5.613 \\
8 & 422 & 2.29 & 81.62 & 163.302 & 49.981 & 49.981 & -- & 1.833 \\
9 & 418 & 4.48 & 113.06 & 199.996 & 56.531 & 56.531 & -- & 1.292 \\
10 & 426 & 1.42 & 83.16 & 160.985 & 51.657 & 51.657 & -- & 3.287 \\
11 & 423 & 0.32 & 30.01 & 115.565 & 33.121 & 25.968 & 9.153 & 1.394 \\
12 & 420 & 5.66 & 114.45 & 279.795 & 40.905 & 40.905 & -- & 2.035 \\
13 & 418 & 4.5 & 85.49 & 184.115 & 46.433 & 46.433 & -- & 1.991 \\
14 & 430 & 2.69 & 78.42 & 177.120 & 44.275 & 44.275 & -- & 1.999 \\
15 & 425 & 1.21 & 36.49 & 196.383 & 19.241 & 18.581 & 0.660 & 0.659 \\
16 & 427 & 1.22 & 67.07 & 155.183 & 43.220 & 43.220 & -- & 3.103 \\
17 & 433 & 0.07 & 1.57 & 70.530 & 2.316 & 2.226 & 0.090 & 0.150 \\
18 & 437 & 2.42 & 175.15 & 221.160 & 79.196 & 79.196 & -- & 0.642 \\
19 & 435 & 2.39 & 212.47 & 268.071 & 79.259 & 79.259 & -- & 0.54 \\
20 & 438 & 1.63 & 133.17 & 168.835 & 78.876 & 78.876 & -- & 0.706 \\
21 & 437 & 1.64 & 150.92 & 189.120 & 79.801 & 79.801 & -- & 0.681 \\
22 & 441 & 1.35 & 103.22 & 160.972 & 64.123 & 64.123 & -- & 1.459 \\
23 & 377 & 1.22 & 31.42 & 54.078 & 58.101 & 58.101 & -- & 0.506 \\
24 & 431 & 3.3 & 224 & 314.744 & 71.169 & 71.169 & -- & 3.212 \\
\hline
\end{tabular}


Table 1. (Continued)

(c) Description, petrographic, and chemical analyses results for samples \#25 - 42.

\begin{tabular}{clcccccccccc}
\hline NO \# & Sample Name & V\% & E\% & I\% & MM\% & N\% & C\% & S\% & H\% & H/C & Ro (\%) \\
\hline 25 & Woodford Shale (P) & 11.6 & 0.2 & 0.2 & 88 & 0.12 & 13.78 & 0.12 & 0.18 & 0.013 & 0.309 \\
26 & Green River (T) & 12.8 & 0 & 0 & 87.2 & 0.94 & 33.21 & 1.42 & 3.76 & 0.113 & 0.281 \\
27 & Green River d $<1.25$ & 0.6 & 16.8 & 0 & 82.6 & 0.92 & 33.04 & 0.64 & 3.98 & 0.120 & 0.214 \\
28 & Green River d $>1.25$ & 4 & 10.2 & 0 & 85.8 & 0.79 & 29.65 & 0.94 & 3.53 & 0.119 & 0.184 \\
29 & Fu Shuan 1 (T) & 87 & 4.6 & 0 & 8.4 & 1.17 & 66.32 & 0.78 & 4.61 & 0.070 & 0.543 \\
30 & Fu Shuan 2(T) & 88.2 & 9.4 & 0.6 & 1.4 & 1.4 & 70.54 & 0.25 & 5.62 & 0.080 & 0.594 \\
31 & Shui Cheng 1 (P) & 80 & 10.8 & 8.8 & 0.4 & 0.98 & 37.74 & 0.40 & 3.70 & 0.098 & 0.58 \\
32 & Shui Cheng 2 (P) & 69.4 & 24.8 & 3.6 & 2.2 & 1.15 & 75.49 & 0.15 & 8.02 & 0.106 & 0.392 \\
33 & Lu Chuan (D) & 6.6 & 1.8 & 0 & 91.6 & 0.64 & 52.48 & 5.31 & 6.03 & 0.115 & 0.451 \\
34 & Jen Chiu 1 (C) & 82.6 & 15.4 & 0.6 & 1.4 & 1.3 & 71.93 & 0.3 & 5.31 & 0.074 & 0.681 \\
35 & Jen Chiu 2 (C) & 71.4 & 4.8 & 22 & 1.8 & 1.47 & 72.67 & 0.73 & 4.48 & 0.062 & 0.586 \\
36 & Shan Shi (C) & 78 & 2.6 & 8.2 & 11.2 & 0.69 & 73.28 & 0.26 & 4.23 & 0.058 & 1.239 \\
37 & San Dao Ling (J) & 61.2 & 6.8 & 32 & 0 & 0.8 & 70.59 & 0.35 & 4.49 & 0.064 & 0.717 \\
38 & Mao Ming (T) & 1.4 & 0.8 & 0 & 97.8 & 0.58 & 6.16 & 1.11 & 3.43 & 0.557 & 0.174 \\
39 & Jiao Tsu (P) & -- & -- & -- & -- & -- & -- & -- & -- & -- & 4.6 \\
40 & Fu Shin (Cr) & 88 & 2.8 & 5.6 & 3.6 & 1.27 & 67.21 & 0.65 & 4.67 & 0.069 & 0.54 \\
41 & Mu Shan (4852) (MF) & 80 & 5.6 & 0 & 14.4 & 0.85 & 51.29 & 4.52 & 3.26 & 0.064 & 1.571 \\
42 & Mu Shan (4860) (MF) & 73 & 3.4 & 0 & 23.4 & 1.12 & 59.63 & 3.43 & 3.43 & 0.057 & 1.562 \\
\hline
\end{tabular}

(d) Rock-Eval Pyrolysis results for samples \#25 - 42.

\begin{tabular}{rcccccccc}
\hline NO \# & Tmax $\left({ }^{\circ} \mathbf{C}\right)$ & S1 (mgHC/g) & S2 (mgHC/g) & $\begin{array}{r}\text { HI (S2/TOC) } \\
\text { mgHC/gTOC }\end{array}$ & TC (\%) & TOC (\%) & IOC (\%) & S (\%) \\
\hline 25 & 440 & 0.52 & 7.9 & 511.990 & 14.963 & 1.543 & 13.420 & 0.034 \\
26 & 428 & 8.47 & 146.53 & 511.484 & 32.656 & 28.648 & 4.008 & 1.054 \\
27 & 430 & 8.81 & 155.32 & 437.509 & 35.501 & 35.501 & -- & 1.030 \\
28 & 428 & 8.07 & 144.61 & 498.535 & 33.320 & 29.007 & 4.313 & 1.040 \\
29 & 429 & 0.74 & 69.44 & 104.209 & 66.635 & 66.635 & -- & 0.566 \\
30 & 429 & 1.17 & 123.13 & 171.152 & 71.942 & 71.942 & -- & 0.426 \\
31 & 450 & 2.08 & 153.41 & 334.132 & 45.913 & 45.913 & -- & 0.232 \\
32 & 453 & 1.78 & 352.47 & 453.962 & 77.643 & 77.643 & -- & 0.403 \\
33 & 444 & 3.11 & 156.04 & 354.379 & 44.032 & 44.032 & -- & 10.288 \\
34 & 429 & 1.44 & 113.15 & 155.362 & 72.830 & 72.830 & -- & 0.670 \\
35 & 432 & 1.27 & 92.18 & 123.963 & 74.361 & 74.361 & -- & 0.588 \\
36 & 445 & 0.6 & 16.89 & 22.996 & 73.446 & 73.446 & -- & 0.178 \\
37 & 432 & 1.98 & 52.79 & 74.211 & 71.135 & 71.135 & -- & 0.575 \\
38 & 426 & 0.48 & 17.37 & 239.026 & 7.267 & 7.267 & -- & 0.973 \\
39 & 488 & 0.32 & 0.08 & 0.097 & 82.219 & 82.219 & -- & 0.395 \\
40 & 430 & 1.15 & 70.09 & 101.720 & 68.905 & 68.905 & -- & 0.416 \\
41 & 477 & 1.84 & 47.76 & 85.470 & 55.879 & 55.879 & -- & 3.578 \\
42 & 479 & 1.44 & 43.87 & 87.092 & 50.372 & 50.372 & -- & 2.699 \\
\hline
\end{tabular}


Miocene). In addition, $\mathrm{H} \%$ is increased in exinite-enriched maceral mixtures with density $<1.25 \mathrm{~g} \mathrm{~cm}^{-3}$, after density centrifuge separation. Most of the vitrinite reflectance measured falls in the range of $0.3 \sim 0.7 \%$, close to the early oil window.

Furthermore, a positive linear correlation between Tmax and Ro can be found (Fig. 1), which illustrates both Rock-Eval pyrolysis and vitrinite reflectance can be used as indicators of thermal maturity. In addition, plotting a curve with $\mathrm{H} / \mathrm{C}$ ratio vs. vitrinite reflectance (Fig. 2), we found that even though the depositional environments were different in Taiwan and China, their organic micelles exhibit a similar trend in the process of thermal maturation. As a whole, the curve has a turning point at $\mathrm{Ro}=0.5 \%$ and $\mathrm{H} / \mathrm{C}=0.1$ (atomic ratio 1.2 ) in this study.

After Person's correlation analysis, not surprisingly, TOC vs C exhibits a strong positive correlation, whereas TOC vs MM, Vitrinite vs MM, and C vs MM exhibit a strong negative correlation. More cross plots of note are further discussed as follows: A rather good correlation between S2 and TOC (Fig. 3) indicates the contribution of S2 from TOC. Both Figs. 4 and 5 illustrate that the highest HI occurs at certain

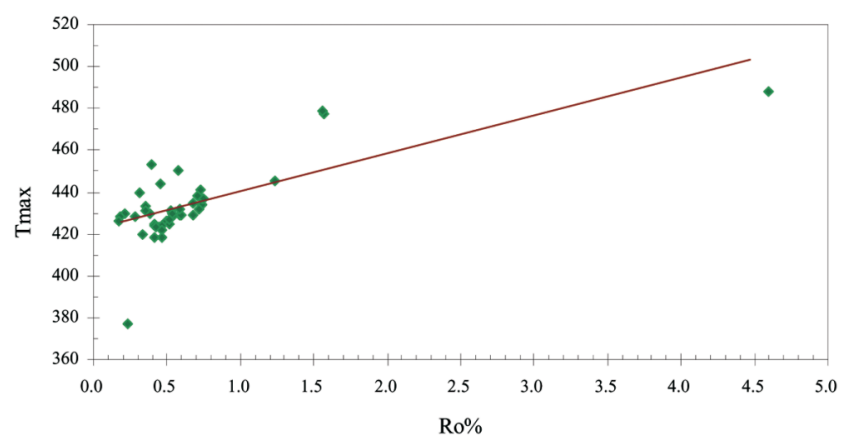

Fig. 1. The linear correlation between Tmax and Ro\% in the samples studied.

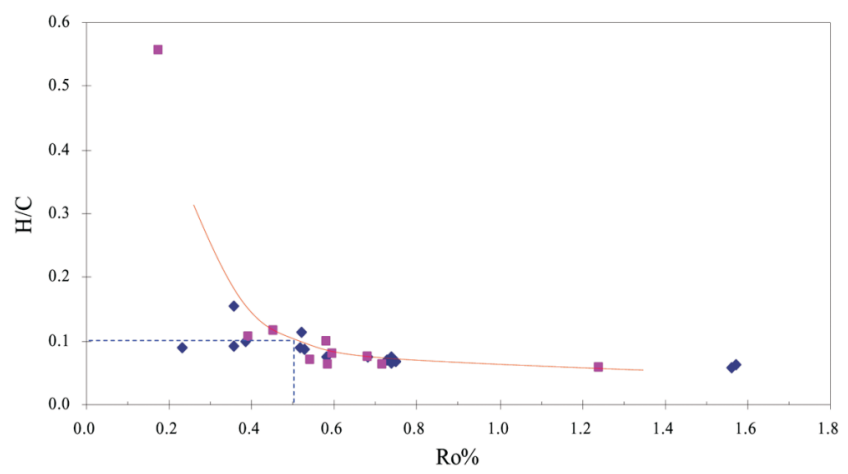

Fig. 2. H/C ratio vs. vitrinite reflectance curve of samples from China $(\square)$ and Taiwan $(\diamond)$. Even though the depositional environments were different, their organic micelles exhibit a similar trend in the process of maturation. As a whole, the curve has a turning point at Ro $=0.5 \%$ and $\mathrm{H} / \mathrm{C}=0.1$ (atomic ratio 1.2). maturities (Tmax and Ro), and does not occur in stages of less maturity or over-maturity. Furthermore, two different trends were observed in the cross plot of S1 vs. S2 (Fig. 6). Generally, field outcropped shale or C-shale exhibits a steeper slope compared to that of coal samples which can be attributed to the compositional difference in organic material. As for the plot of HI vs. TOC (Fig. 7), no significant trend can be found, although the Green River and Woodford oil shale from the U.S. exhibit the highest HI with notso-much TOC contents. Finally, a rather strong positive correlation of $\mathrm{H} \%$ vs. S2 was found in Fig. 8, which illustrates the contribution of $\mathrm{H}$-containing macerals, especially exinite.

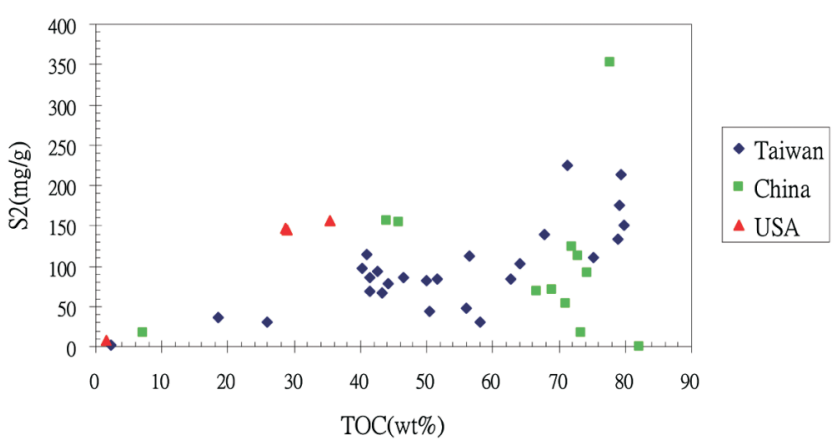

Fig. 3. Correlation between S2 and TOC of samples studied.

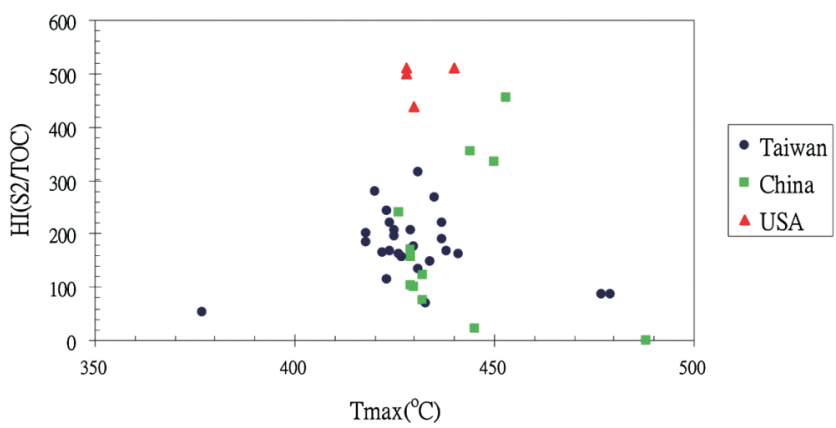

Fig. 4. Correlation between HI and Tmax of samples studied.

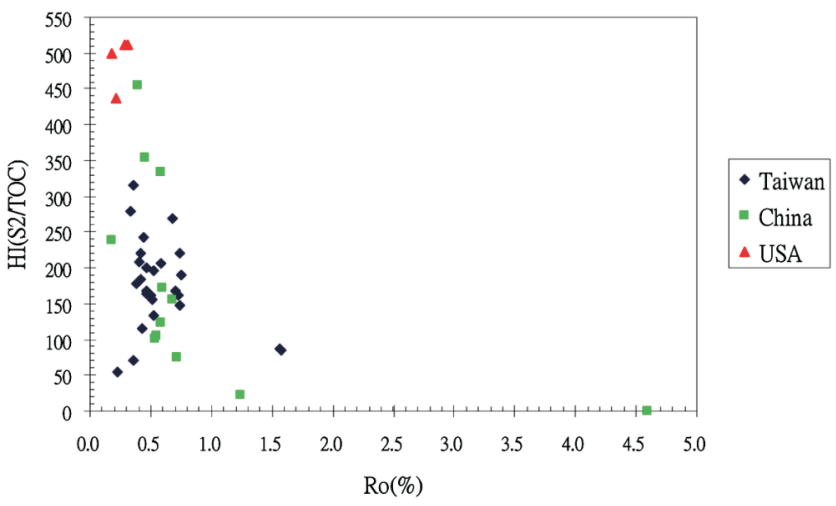

Fig. 5. Correlation of HI and Ro of samples studied. 


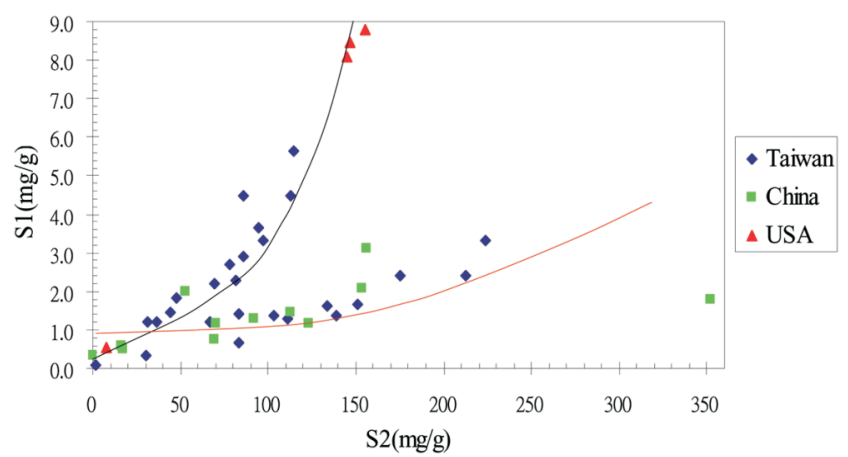

Fig. 6. Correlation between S1 and S2 of samples studied. Two linear trends with positive slope can be observed; black lines and red lines were drawn from $\mathrm{C}$-shale samples and coal samples, respectively.

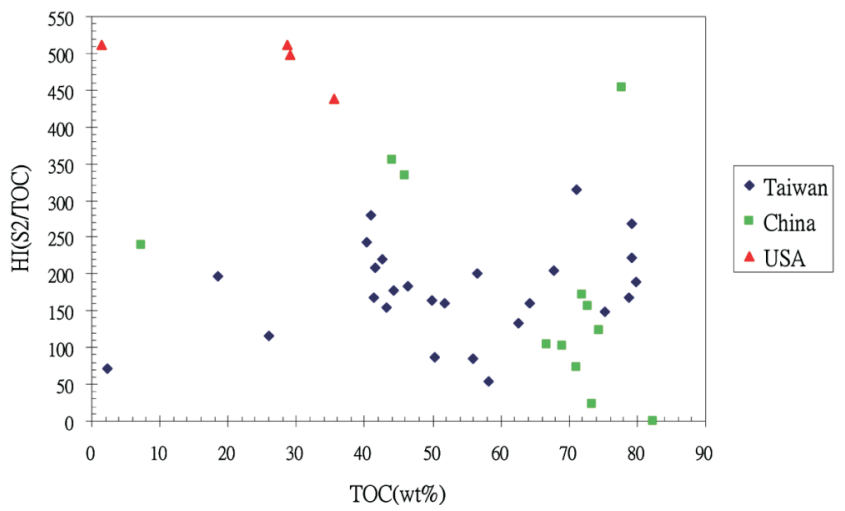

Fig. 7. Correlation between $\mathrm{HI}$ and TOC of samples studied.

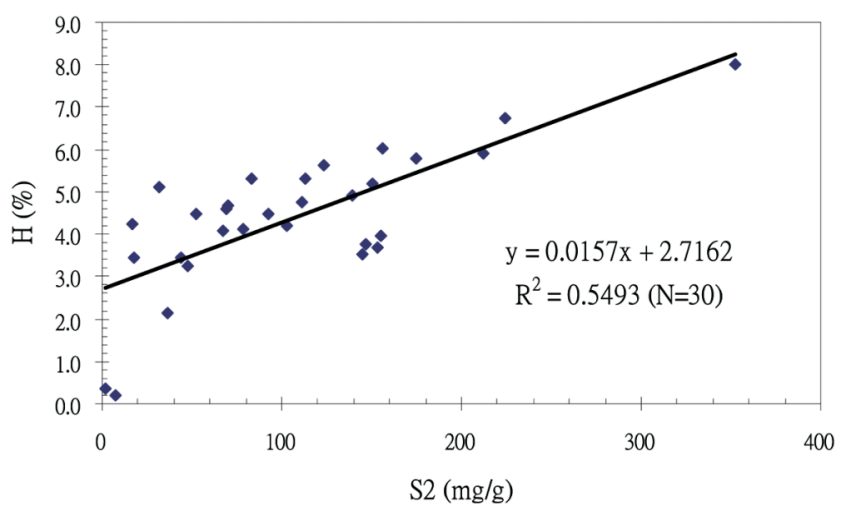

Fig. 8. Correlation of $\mathrm{H}$ and $\mathrm{S} 2$ of all samples studied.

\section{CONCLUSION}

(1) Coal samples from the Shiti Formation (middle Miocene) exhibit more vitrinite and less mineral matter contents than samples from the Nanchuang Formation (upper Miocene). In addition, $\mathrm{H} \%$ is increased in exiniteenriched maceral mixtures with density $<1.25 \mathrm{~g} \mathrm{~cm}^{-3}$, after density centrifuge separation.

(2) A positive linear correlation between Tmax and Ro illus- trates both Rock-Eval pyrolysis and vitrinite reflectance can be used as indicators of thermal maturity.

(3) From the plot of $\mathrm{H} / \mathrm{C}$ ratio vs. vitrinite reflectance, even though the depositional environments were different in Taiwan and China, their organic micelles exhibit a similar trend in the process of thermal maturation. As a whole, the curve has a turning point at Ro $=0.5 \%$ and $\mathrm{H} / \mathrm{C}=0.1$ (atomic ratio 1.2) in this study.

(4) A rather good correlation between S2 and TOC of samples studied indicates the contribution of S2 from TOC.

(5) The highest HI occurred in certain maturities (Tmax and Ro) of samples studied, and not in the stages of less maturity or over-maturity.

(6) Two different linear trends were observed in the cross plot of S1 vs. S2. Field outcropped shale or C-shale exhibits a steeper slope compared to that of coal samples which can be attributed to the compositional difference in their organic material.

(7) A rather strong positive correlation of $\mathrm{H} \%$ vs. S2 illustrates the contribution of $\mathrm{H}$-containing macerals, especially exinite.

As a result of this study, we expect to promote evaluation techniques for $\mathrm{HC}$ exploration; for instance, the development or improvement of evaluation methods for source rocks, reservoirs, structural evolution, and thermal maturity. Evaluations are expected to give more detail on local conditions, and be better quantified and more accurate.

Acknowledgements The authors would like to give thanks to the anonymous reviewers of this manuscript for giving constructive suggestions and revision comments. Special thanks to the faculty and staff of the Geochemical Department of Exploration and Development Research Institute, CPC, for providing valuable samples and analysis assistance. This research was financially supported by Grants 91-F0107-3-6 and 93-F0108-2-1 of the Petroleum Fund.

\section{REFERENCES}

Chi, W. R., W. H. Wang, D. L. Lu, L. H. Lin, and R. C. Wu, 1987: The application of back-stripping method in basin analysis and oil exploration of the Peikang area. Bull. Explor. \& Prod. Res., CPC, 10, 63-88.

Chiu, H. T., 1972: Miocene stratigraphy of the Nantou area, central Taiwan. Petrol. Geol. Taiwan, 10, 159-177.

Chiu, H. T., 1975: Miocene stratigraphy and its relation to the Paleogene rocks in western-central Taiwan. Petrol. Geol. Taiwan, 12, 51-80.

Dormans, H. N. M., F. J. Huntjens, and D. W. Van Krevelen, 1957: Chemical structure and properties of coal-composition of the individual macerals (vitrinites, fusinites, micrinites and exinites). Fuel, 36, 321-339.

Dow, W. G., 1974: Application of oil correlation source rock 
data to exploration in Williston basin. AAPG Bull., 58, 1253-1262.

Hsiao, P. T., C. C. Hu, K. A. Lin, S. H. Hsu, S. C. Fuh, T. Y. Chang, T. H. Hsiuan, H. C. Sheen, C. L. Kuo, and C. J. Lee, 1991: Hydrocarbon potential evaluation of the Penghu Basin. Petrol. Geol. Taiwan, 26, 215-229.

Huang, C. Y., 1984: Late Oligocene benthic foraminifera assemblages in northern Taiwan. The Second International Symposiumon Benthic Foraminifera, Pau, France, 6, 317323.

Huang, C. Y., 1986: Oligocene and Miocene stratigraphy of the Kuohsing area, central Taiwan. Acta Geol. Taiwan., 24, 281-318.

Hwang, W. T. and C. Y. Wang, 1993: Sequential thrusting model for mountain building - constrains from geology and heat flow of Taiwan. J. Geophys. Res., 98, 9963-9973.

Lin, C. H., 2000: Thermal modeling of continental subduction and exhumation constrained by heat flow and seismicity in Taiwan. Tectonophysics, 324, 189-201.

Liou, C. H. and C. Y. Hsu, 1988: Petroleum exploration on the southwestern plain of Taiwan. Petrol. Geol. Taiwan, 24, 18-36.

Magoon, L. B. and W. G. Dow, 1994: The petroleum system from source to trap. AAPG Mem., 60, $655 \mathrm{pp}$.

Otis, R. M. and N. Schneidermann, 1997: A process for evaluating exploration prospects. AAPG Bull., 81, 1087-1109.

Sun, S. C., 1982: The Tertiary basin of offshore Taiwan. Proceedings. $2^{\text {nd }}$ ASCOPE Conference and Exhibition, 125-135.

Sun, S. C., 1985: The Cenozoic tectonic evolution of offshore Taiwan. Energy, 10, 421-432. 